\title{
Penerapan Rantai Markov Dalam Pemilihan Minat Masuk Siswa SMA Ke Universitas Di Indonesia
}

\author{
Sitty Nurjana ${ }^{1}$, Marline S. Paendong ${ }^{2}$, Yohanes A. R. Langi ${ }^{3}$ \\ ${ }^{1}$ Program Studi Matematika, FMIPA, UNSRAT Manado, sitty.nurjana@gmail.com \\ ${ }^{2}$ Program Studi Matematika, FMIPA, UNSRAT Manado, marline.paendong16@gmail.com \\ ${ }^{3}$ Program Studi Matematika, FMIPA, UNSRAT Manado, varlangi@gmail.com
}

\begin{abstract}
Abstrak
Analisis Rantai Markov adalah suatu metode yang mempelajari sifat-sifat suatu variabel pada masa sekarang yang didasarkan pada sifat-sifatnya di masa lalu dalam usaha menaksir sifat-sifat variabel tersebut dimasa yang akan datang. Penelitian ini bertujuan untuk mengetahui besarnya perpindahan peluang pemilihan minat siswa SMA ke universitas di Indonesia dengan menggunakan metode Rantai Markov berdasarkan data dari siswa kelas XII IPA SMA Negeri 09 Manado dan siswa kelas XII IPA SMA Negeri 01 Manado terhadap pemilihan universitas negeri maupun swasta dari tahun 2016 sampai tahun 2018. Data sampel terdiri dari 315 siswa yang berasal dari siswa kelas XII IPA SMA Negeri 09 Manado sebanyak 100 orang dan siswa kelas XII IPA SMA Negeri 01 Manado sebanyak 215 orang. Dari hasil penelitian menunjukkan bahwa Rantai Markov dapat digunakan untuk memprediksi peluang perpindahan pemilihan universitas terhadap minat siswa dalam memilih universitas di Indonesia, maka dapat diambil kesimpulan sebagai berikut : untuk universitas pangsa pasar periode pertama pada tahun 2016 di dominasi oleh UNSRAT sebesar 39\%, kemudian diikuti oleh UNIMA $21 \%$, UGM 7\%, ITB 7\%, UI 6. $\%$, UNPAD 5\%, UBM 2\%, UNUD 2\%, POLTEKES $2 \%$, UNAIR 1\%, UPH 3\% dan Lainnya 4\%. Sedangkan pangsa pasar periode berikutnya pada tahun 2018 peluang berubah, walaupun tetap masih di dominasi oleh UNSRAT 41\%, UNIMA 21\%, UGM $8 \%$, ITB 9\%, UI 5\%, UNPAD 6\%, UBM 1\%, UNUD 2\%, POLTEKES $1 \%$, UNAIR $1 \%$, UPH $2 \%$ dan Lainnya $3 \%$.
\end{abstract}

Kata kunci : Rantai Markov, Pangsa pasar, SMA, Universitas

\section{Application of Markov Chain Interest Sign In Elections High School Students To University In Indonesia}

\begin{abstract}
Markov Chain Analysis is a method of studying the properties of a variable at the present time based on its properties in the past in an attempt to assess the properties of these variables in the future. This study aims to determine the amount of chances electoral interests of high school students to universities in Indonesia using Markov Chain based on data from students of class XII IPA SMA Negeri 09 Manado and students of class XII IPA SMA Negeri 01 Manado on the selection of state and private universities from 2016 until 2018. the data sample consists of 315 students from class XII students of SMA Negeri Manado 09100 people and students of class XII IPA SMA Negeri 01 Manado as many as 215 people. The results showed that the Markov chain can be used to predict the chances of displacement electoral college to interest students in choosing a university in Indonesia, it can be concluded as follows: for the university market share of the first period in 2016 was dominated by UNSRAT by 39\%, followed by UNIMA 21\%, 7\% UGM, ITB 7\%, 6\% UI, UNPAD 5\%, UBM 2\%, 2\% UNUD, POLTEKES 2\%, $1 \%$ UNAIR, UPH 3\% and 4\% Other. While the market share of the next period in 2018 the opportunity to change, although still dominated by UNSRAT 41\%, UNIMA 21\%, UGM 8\%, ITB 9\%, UI 5\%, UNPAD 6\%, UBM 1\%, UNUD 2\%, POLTEKES 1\%, UNAIR 1\%, UPH $2 \%$ and Other $3 \%$.
\end{abstract}

Keywords : Markov Chain, Market share, High School, University

\section{Pendahuluan}

Universitas harus dapat menganalisis pangsa pasar untuk meningkatkan mutu pendidikan perguruan tinggi sebagai target utama universitas dalam mengetahui penilaian pangsa pasar para pelajar SMA terhadap universitas. Hal ini dikarenakan banyaknya pilihan universitas dan program studi yang ditawarkan serta adanya perubahan selera konsumen terhadap perpindahan minat pelajar terhadap suatu universitas ke universitas yang lainnya dalam jangka waktu tertentu. 
Pangsa pasar (market share) dapat diartikan sebagai bagian pasar yang dikuasai oleh suatu perusahaan, atau persentasi penjualan suatu perusahaan terhadap total penjualan para pesaing terbesarnya pada waktu dan tempat tertentu. Besarnya pangsa pasar setiap saat akan berubah sesuai dengan perubahan selera konsumen, atau berpindahnya minat konsumen dari suatu produk ke produk lain [1].

Salah satu teknik untuk memprediksi pangsa pasar di waktu yang akan datang adalah dengan menggunakan analisis Rantai Markov (Markov Chain). Analisis Markov merupakan sebuah metode dalam menganalisis perilaku saat ini dari beberapa variabel, dengan tujuan untuk memprediksi perilaku siswa SMA terhadap perpindahan pemilihan universitas di Indonesia . Dengan demikian, Rantai Markov akan menjelaskan gerakan-gerakan beberapa variabel dalam satu periode waktu di masa yang akan datang berdasarkan pada gerakan-gerakan variabel tersebut di masa kini [2].

\section{Proses Stokastik}

Proses stokastik $X=\{X(t), t \in T\}$ adalah suatu koleksi (gugus,himpunan, atau kumpulan) dari peubah acak (random variable) yang memetakkan suatu ruang contoh (sample space) $\Omega$ ke suatu ruang state (state space) $\mathrm{S}$. Untuk setiap $t$ pada gugus (himpunan) indeks $\mathrm{T}, \mathrm{X}(t)$ adalah suatu peubah acak. Dimana $t$ sebagai waktu (meskipun dalam berbagai penerapannya t tidak selalu menyatakan waktu), dan $\mathrm{X}(t)$ sebagai state (keadaan) dari proses pada waktu $t$ [3].

\section{Rantai Markov}

Rantai markov rmerupakan proses acak di mana semua informasi tentang masa depan terkandung di dalam keadaan sekarang (yaitu orang tidak perlu memeriksa masa lalu untuk menentukan masa depan). Untuk lebih tepatnya, proses memiliki properti Markov, yang berarti bahwa bentuk ke depan hanya tergantung pada keadaan sekarang, dan tidak bergantung pada bentuk sebelumnya. Dengan kata lain, gambaran tentang keadaan sepenuhnya menangkap semua informasi yang dapat mempengaruhi masa depan dari proses evolusi [3].

Dalam analisis Markov yang dihasilkan adalah suatu informasi probabilistik yang dapat digunakan untuk membantu pembuatan keputusan. Jadi analisis ini bukan teknik optimasi melainkan suatu teknik deskriptif. Jika pada waktu $t$ proses stokastik $\left\{X_{t}, t=0,1, \ldots\right\}$ berada pada state $i$.Terdapat suatu peluang tetap $P_{i j}$ yang bersifat bebas terhadap waktu maka berlaku:

$$
\begin{aligned}
& P\left\{X_{t=1}=j \mid X_{0}=i_{0}, \ldots, X_{t-1}=i_{t-1}, X_{t}=i\right\}=p\left\{X_{t+1}=j \mid X_{t}=i\right\} \\
& \text { Dimana } i=\text { state ke-i } \\
& \mathrm{j}=\text { state ke-j } \\
& \mathrm{t}=\text { waktu } \\
& i_{0}, \ldots, i_{t-1}, i, j \text { dan semua } t \geq 0 \text { [4]. }
\end{aligned}
$$

a) Peluang transisi

Rantai markov $\left\{X_{t}, t=0,1,2, \ldots\right\}$ dengan ruang state $\{0,1, \ldots, M\}$, maka peluang sistem itu dalam state $i$ pada suatu state $j$ pada pengamatan sebelumnya dilambangkan dengan P. Matriks peluang transisi rantai Markov, dimana elemen-elemen dari matriks $\mathbf{P}$ bernilai positif dan jumlah elemen-elemennya pada satu baris di matriks peluang transisi ini harus sama dengan 1 (satu) [5].

$$
\begin{aligned}
& \text { State akhir } \\
& \left.\begin{array}{cccccc}
\text { Jadi, } & & i_{0} & i_{1} & i_{2} & \ldots \\
& i_{0} & \mathbf{P}=\text { state awal } & i_{1} \\
& i_{2} \\
& \vdots & p_{0.0} & p_{0,1} & p_{0,2} & \ldots \\
p_{1,0} & p_{1,1} & p_{1,2} & \ldots \\
p_{2,0} & p_{2,1} & p_{2,2} & \ldots \\
\vdots & \vdots & \vdots & \ldots
\end{array}\right]
\end{aligned}
$$

b) Peluang transisi $n$-step

Peluang transisi $n$-step $P_{i, j}^{(n)}$ adalah peluang bersyarat suatu sistem yang berada pada state $i$ akan berada pada state $j$ setelah proses mengalami $n$ transisi [6]. Jadi : 


$$
P_{i, j}^{(n)}=\left\{\mathrm{X}_{\mathrm{n}}=j \mid \mathrm{X}_{0}=i, i, j \in\{0,1,2, \ldots\}\right.
$$

Untuk setiap $n=1,2, \ldots$ Tentunya $P_{i, j}^{(1)}=P_{i, j}$.

Nilai $p_{i, j}$ di atas menyatakan peluang bahwa, jika proses tersebut berada pada state i, maka berikutnya akan beralih ke state $j$. Karena nilai peluang adalah tak negatif dan karena poses tersebut harus mengalami transisi ke suatu state, maka :

(i) $\quad p_{i, j} \geq 0$, untuk semua $i, j \in\{0,1,2, \ldots\}$,

(ii) $\quad \sum_{j=0}^{\infty} p_{i, j}=1$, untuk semua $i \in\{0,1,2, \ldots\}$.

\section{c) Persamaan Chapman Kolmogorov}

Persamaan Chapman-Kolmogorov merupakan sebuah metode untuk menghitung peluang transisi dalam $n$-step. Persamaan Chapman-Kolmogorov memberikan metode untuk menentukan transisi $n$-step [3].

$$
P_{i j}^{(n)}=\sum_{k=0}^{M} P_{i k}^{(m)} P_{k j}^{(n-m)}
$$

Untuk semua $P_{i, j}=$ Peluang dari state $\mathrm{i}$ ke state $\mathrm{j}$

$P_{i k}=$ Peluang dari state i ke state $\mathrm{k}$

$P_{k j}=$ Peluang dari state $\mathrm{k}$ ke state $\mathrm{j}$

$\mathrm{i}, \mathrm{j}=1,2, \ldots, \mathrm{M}$

$\mathrm{m}=1,2, \ldots, \mathrm{n}-1$

$\mathrm{n}=\mathrm{m}+1, \mathrm{~m}+2, \ldots$

d) Peluang steady state

Suatu state disebut berulang positif (positive recurrent) jika state tersebut adalah berulang (recurrent). Sebaran steady state sering juga disebut sebaran stasioner atau sebaran setimbang (equilibrium distribution) dari proses rantai markov [3].

Variabel dalam satu periode waktu dimasa yang akan datang berdasarkan pada gerakangerakan variabel pada masa sekarang, persamaan sebagai berikut: [2].

dimana :

$$
K_{t(j)}=P \times K_{t(j-1)}
$$

$$
\begin{array}{ll}
K_{t(j)} & =\text { Peluang kejadian pada } t(j) \\
P & =\text { Probabilitas Transisional } \\
t(j) & =\text { Waktu ke- } j
\end{array}
$$

\section{Metodologi Penelitian}

\subsection{Waktu dan Tempat Penelitian}

Penelitian dilakukan pada bulan Februari 2016 sampai April 2016. Tempat penelitian dilaksanakan di SMA Negeri 09 Manado dan SMA Negeri 01 Manado. Pengolahan data dilakukan di Laboratorium Statistika Program Studi Matematika Fakultas MIPA Universitas Sam Ratulangi.

\subsection{Data dan Variabel Penelitian}

Penelitian ini menggunakan data primer. Data penelitian atau sumber data ini didapatkan secara langsung dari pelajar kelas XII IPA SMA Negeri 09 Manado dan kelas XII IPA SMA Negeri 01 Manado sebagai data penelitian. Jenis data penelitian yang digunakan bersifat kualitatif dan kuantitatif dari hasil kuesioner. Teknik pengumpulan data yang digunakan dalam penelitian ini yaitu dengan penyebaran kuesioner secara langsung terhadap siswa kelas XII IPA SMA Negeri 09 Manado sebanyak 100 responden dan siswa kelas XII IPA SMA Negeri 01 Manado sebanyak 215 responden. 


\subsection{Tahapan Analisis Data}

Analisis data yang digunakan dalam penelitian ini adalah :

1) Uji validalitas dan reliabilitas terhadap kuesioner dengan menggunakan bantuan software.

2) Analisis statistik deskriptif, yaitu mengenai sumber refrensi pelajar dalam pemelihan universitas, penilaian pelajar terhadap universitas yang dipilih, universitas yang paling diminati berdasarkan prioritas dan data pemilihan universitas. Analisis statistik deskriptif dilakukan dengan menggunakan software.

3) Menentukan pangsa pasar (market share) dan klasifikasi universitas dalam matriks peluang transisi dari analisis rantai markov.

4) Menentukan pola perpindahan universitas yang satu ke universitas yang lain dengan sumber data dari pertanyaan nomor 2 (dua) pada hasil kuesioner maka dapat dibuat periode pertama sebagai market share atau peluang pertama memilih universitas dan periode kedua sebagai peluang kedua perpindahan dari universitas sebelumnya.

5) Analisis Markov, yaitu mengenai pendugaan permintaan pada periode berikutnya dan pendugaan peminatan pada titik ekuilibrum dengan menggunakan software.

\section{Hasil dan Pembahasan}

\subsection{Data Pemilihan Universitas Periode 1}

Pengolahan data terhadap pemilihan universitas pada periode 1 disajikan pada Tabel 1.

Tabel 1. Jumlah Pemilih, Probabilitas dan Proporsi pada berbagai Universitas pada kedua SMA Negeri di Manado Periode 1

\begin{tabular}{|c|l|c|c|c|c|}
\hline No & \multicolumn{1}{|c|}{ Nama Universitas } & State & $\begin{array}{c}\text { Jumlah } \\
\text { Responden }\end{array}$ & Probabilitas & $\begin{array}{c}\text { Proporsi } \\
(\%)\end{array}$ \\
\hline 1 & Universitas Sam Ratulangi & State 1 & 165 & 0.52 & $52 \%$ \\
\hline 2 & Universitas Gajah Mada & State 2 & 28 & 0.09 & $9 \%$ \\
\hline 3 & Institut Teknologi Bandung & State 3 & 16 & 0.05 & $5 \%$ \\
\hline 4 & Universitas Negeri Manado & State 4 & 15 & 0.05 & $5 \%$ \\
\hline 5 & Universitas Indonesia & State 5 & 14 & 0.04 & $4 \%$ \\
\hline 6 & Universitas Padjadjaran & State 6 & 13 & 0.04 & $4 \%$ \\
\hline 7 & Universitas Brawijaya Malang & State 7 & 11 & 0.03 & $3 \%$ \\
\hline 8 & Poltekes & State 8 & 8 & 0.03 & $3 \%$ \\
\hline 9 & Universitas Udayana & State 9 & 8 & 0.03 & $3 \%$ \\
\hline 10 & Universitas Airlangga & State 10 & 8 & 0.03 & $3 \%$ \\
\hline 11 & Universitas Pelita Harapan & State 11 & 7 & 0.02 & $2 \%$ \\
\hline 12 & Lainnya & State 12 & 22 & 0.07 & $7 \%$ \\
\hline & & 315 & 1 & $100 \%$ \\
\hline
\end{tabular}

Jika probabilitas tersebut di letakkan dalam vektor probabilitas state maka akan menjadi : Dimana :

$$
\pi(1)=(0.52,0.09,0.05,0.05,0.04,0.04,0.03,0.03,0.03,0.03,0.02,0.07)
$$

$\boldsymbol{\pi}(\mathbf{1})=$ Vektor probabilitas state ke-12 universitas untuk periode 1

$\boldsymbol{\pi}_{\mathbf{1}}=\mathbf{0 . 5 2}=$ probabilitas satu orang yang memilih UNSRAT, state 1

$\boldsymbol{\pi}_{\mathbf{2}}=\mathbf{0 . 0 9}=$ probabilitas satu orang yang memilih UGM, state 2

$\pi_{3}=\mathbf{0 . 0 5}=$ probabilitas satu orang yang memilih ITB, state 3

$\boldsymbol{\pi}_{\mathbf{4}}=\mathbf{0 . 0 5}=$ probabilitas satu orang yang memilih UNIMA, state 4

$\boldsymbol{\pi}_{\mathbf{5}}=\mathbf{0 . 0 4}=$ probabilitas satu orang yang memilih UI, state 5

$\boldsymbol{\pi}_{\mathbf{6}}=\mathbf{0 . 0 4}=$ probabilitas satu orang yang memilih UNPAD, state 6

$\pi_{7}=\mathbf{0 . 0 3}=$ probabilitas satu orang yang memilih UBM, state 7

$\boldsymbol{\pi}_{\mathbf{8}}=\mathbf{0 . 0 3}=$ probabilitas satu orang yang memilih POLTEKES, state 8

$\boldsymbol{\pi}_{\mathbf{9}}=\mathbf{0 . 0 3}=$ probabilitas satu orang yang memilih UNUD, state 9

$\boldsymbol{\pi}_{\mathbf{1 0}}=\mathbf{0 . 0 3}=$ probabilitas satu orang yang memilih UNAIR, state 10

$\boldsymbol{\pi}_{\mathbf{1 1}}=\mathbf{0 . 0 2}=$ probabilitas satu orang yang memilih UPH, state 11

$\boldsymbol{\pi}_{\mathbf{1 2}}=\mathbf{0 . 0 7}=$ probabilitas satu orang yang memilih Lainnya, state 12 


\subsection{Data Pemilihan Universitas Periode 2}

Tabel 2. Jumlah Pemilih, Probabilitas dan Proporsi pada berbagai Universitas pada kedua SMA Negeri di Manado Periode 2

\begin{tabular}{|c|l|c|c|c|c|}
\hline No & \multicolumn{1}{|c|}{ Nama Universitas } & State & $\begin{array}{c}\text { Jumlah } \\
\text { Responden }\end{array}$ & Probabilitas & $\begin{array}{c}\text { Proporsi } \\
(\%)\end{array}$ \\
\hline 1 & Universitas Sam Ratulangi & State 1 & 124 & 0.39 & $39 \%$ \\
\hline 2 & Universitas Negeri Manado & State 2 & 63 & 0.2 & $20 \%$ \\
\hline 3 & Universitas Gajah Mada & State 3 & 26 & 0.08 & $8 \%$ \\
\hline 4 & Universitas Indonesia & State 4 & 21 & 0.07 & $7 \%$ \\
\hline 5 & Institut Teknologi Bandung & State 5 & 21 & 0.07 & $7 \%$ \\
\hline 6 & Universitas Padjadjaran & State 6 & 16 & 0.05 & $5 \%$ \\
\hline 7 & Universitas Udayana & State 7 & 8 & 0.03 & $3 \%$ \\
\hline 8 & Poltekes & State 8 & 7 & 0.02 & $2 \%$ \\
\hline 9 & Universitas Brawijaya Malang & State 9 & 7 & 0.02 & $2 \%$ \\
\hline 10 & Universitas Airlangga & State 10 & 4 & 0.01 & $1 \%$ \\
\hline 11 & Universitas Pelita Harapan & State 11 & 4 & 0.01 & $1 \%$ \\
\hline 12 & Lainnya & State 12 & 14 & 0.05 & $5 \%$ \\
\hline & & 315 & 1 & $100 \%$ \\
\hline
\end{tabular}

Penelitian pada periode kedua menunjukkan adanya perpindahan dari universitas yang satu ke universitas yang lain.

Tabel 3. Jumlah Pemilih Universitas Sebelumnya dan Saat Ini.

\begin{tabular}{|c|l|c|c|c|c|}
\hline No. & \multicolumn{1}{|c|}{ Nama Universitas } & $\begin{array}{c}\text { Jumlah } \\
\text { Universitas } \\
\text { Sebelummnya }\end{array}$ & Perolehan & Kehilangan & $\begin{array}{c}\text { Jumlah } \\
\text { Universitas } \\
\text { Saat ini }\end{array}$ \\
\hline 1 & Universitas Sam Ratulangi & 165 & 85 & 126 & 124 \\
\hline 2 & Universitas Negeri Manado & 15 & 58 & 10 & 63 \\
\hline 3 & Universitas Gajah Mada & 28 & 21 & 23 & 26 \\
\hline 4 & Institut Teknologi Bandung & 16 & 17 & 12 & 21 \\
\hline 5 & Universitas Indonesia & 14 & 21 & 14 & 21 \\
\hline 6 & Universitas Padjadjaran & 13 & 12 & 9 & 16 \\
\hline 7 & Universitas Brawijaya Malang & 11 & 4 & 8 & 7 \\
\hline 8 & Universitas Udayana & 8 & 8 & 8 & 8 \\
\hline 9 & Poltekes & 8 & 4 & 5 & 7 \\
\hline 10 & Universitas Airlangga & 8 & 4 & 8 & 4 \\
\hline 11 & Universitas Pelita Harapan & 7 & 3 & 6 & 4 \\
\hline 12 & Lainnya & 22 & 13 & 21 & 14 \\
\hline & $\quad 315$ & 250 & 250 & 315 \\
\hline
\end{tabular}

Tabel 4. Pola Perpindahan Universitas Perolehan dan Kehilangan

\begin{tabular}{|c|c|c|c|c|c|c|c|c|c|c|c|c|c|}
\hline \multirow[b]{2}{*}{ Universitas } & \multicolumn{13}{|c|}{ Ke Universitas } \\
\hline & 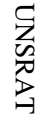 & $\underset{3}{g}$ & $\begin{array}{l}\check{L} \\
\stackrel{3}{3}\end{array}$ & $\vec{\exists}$ & $\subseteq$ & $\underset{Z}{Z}$ & $\underset{5}{\mathfrak{w}}$ & $\underset{\Xi}{\Xi}$ & 突兽 & 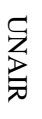 & $\underset{T}{\overparen{I}}$ & 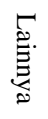 & $\begin{array}{l}\text { Responden } \\
\text { Sebelumnya }\end{array}$ \\
\hline UNSRAT & 39 & 47 & 13 & 15 & 17 & 7 & 3 & 5 & 4 & 4 & 3 & 8 & 165 \\
\hline UNIMA & 6 & 5 & 1 & 2 & 0 & 1 & 0 & 0 & 0 & 0 & 0 & 0 & 15 \\
\hline UGM & 17 & 0 & 5 & 0 & 2 & 1 & 0 & 2 & 0 & 0 & 0 & 1 & 28 \\
\hline ITB & 9 & 1 & 1 & 4 & 0 & 0 & 0 & 0 & 0 & 0 & 0 & 1 & 16 \\
\hline UI & 9 & 1 & 4 & 0 & 0 & 0 & 0 & 0 & 0 & 0 & 0 & 0 & 14 \\
\hline UNPAD & 9 & 0 & 0 & 0 & 0 & 4 & 0 & 0 & 0 & 0 & 0 & 0 & 13 \\
\hline UBM & 5 & 1 & 0 & 0 & 0 & 1 & 3 & 0 & 0 & 0 & 0 & 1 & 11 \\
\hline UNUD & 6 & 2 & 0 & 0 & 0 & 0 & 0 & 0 & 0 & 0 & 0 & 0 & 8 \\
\hline
\end{tabular}




\begin{tabular}{|c|c|c|c|c|c|c|c|c|c|c|c|c|c|}
\hline \multirow[b]{2}{*}{ Universitas } & \multicolumn{13}{|c|}{ Ke Universitas } \\
\hline & 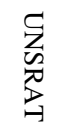 & $\frac{5}{3}$ & $\begin{array}{l}\complement \\
\text { ڤ } \\
3\end{array}$ & $\bar{\Xi}$ & $\subseteq$ & $\stackrel{5}{\mathrm{Z}}$ & $\underset{\Xi}{\varpi}$ & 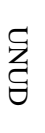 & 葸蛋 & 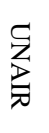 & $\underset{T}{T}$ & 氖. & $\begin{array}{l}\text { Responden } \\
\text { Sebelumnya }\end{array}$ \\
\hline POLTEKES & 3 & 0 & 0 & 0 & 0 & 1 & 0 & 0 & 3 & 0 & 0 & 1 & 8 \\
\hline UNAIR & 7 & 0 & 0 & 0 & 0 & 0 & 0 & 1 & 0 & 0 & 0 & 0 & 8 \\
\hline UPH & 5 & 0 & 0 & 0 & 0 & 0 & 0 & 0 & 0 & 0 & 1 & 1 & 7 \\
\hline Lainnya & 9 & 6 & 2 & 0 & 2 & 1 & 1 & 0 & 0 & 0 & 0 & 1 & 22 \\
\hline $\begin{array}{l}\text { Responden } \\
\text { Saat Ini }\end{array}$ & 124 & 63 & 26 & 21 & 21 & 16 & 7 & 8 & 7 & 4 & 4 & 14 & 315 \\
\hline
\end{tabular}

\subsection{Prediksi Masing-masing Pemilih Universitas Favorit pada Kedua SMA Negeri di \\ Manado}

Bila diasumsikan bahwa perpindahan pemilihan universitas favorit stabil maka dapat dibuat matriks peluang transisi $\mathbf{P}$.

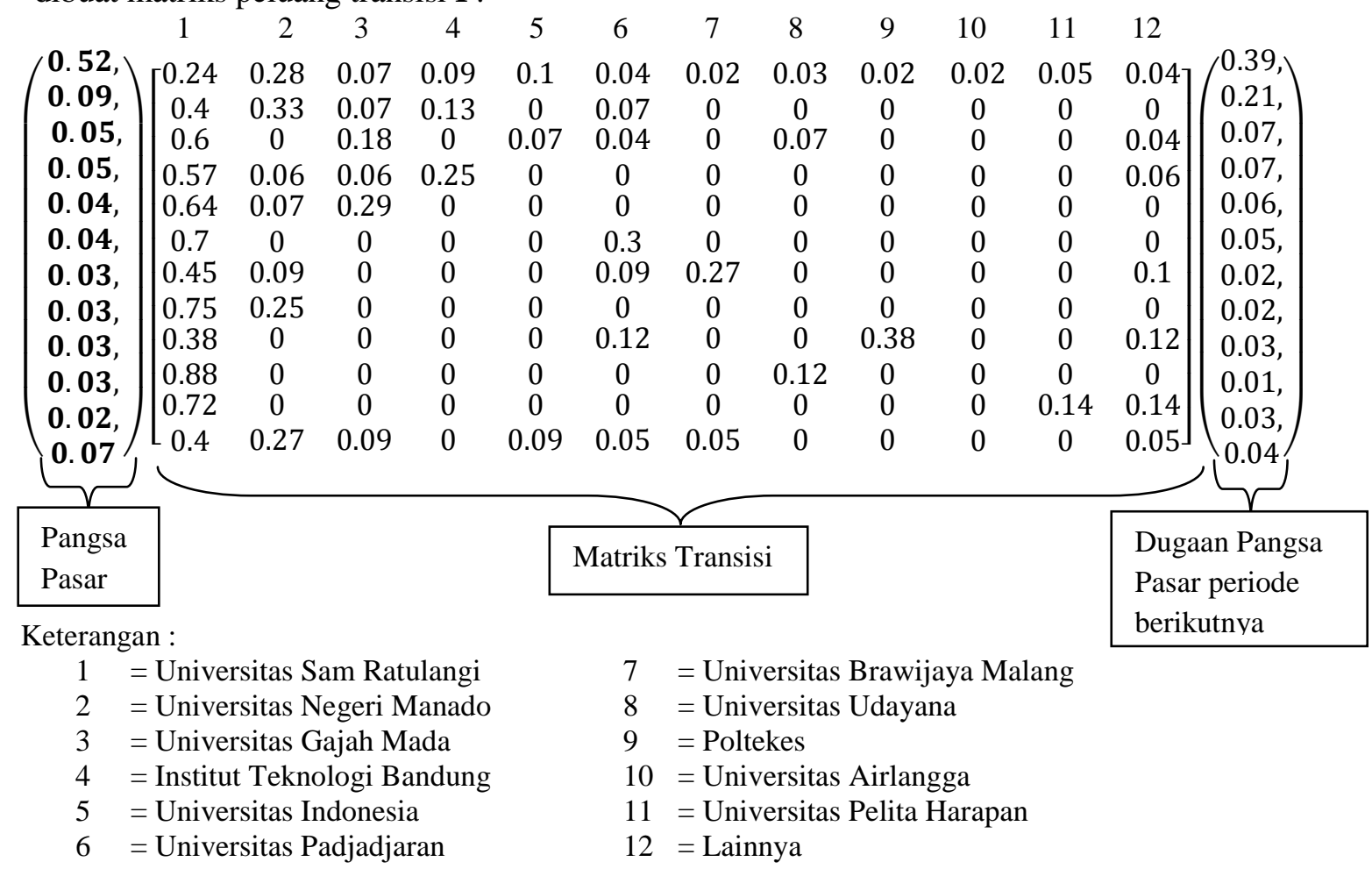

Tabel 5. Prediksi Masing-masing Universitas pada kedua SMA Negeri di Manado dari Tahun 2016 Sampai dengan Tahun 2018.

\begin{tabular}{|l|c|c|c|}
\hline \multirow{2}{*}{ Universitas } & \multicolumn{3}{|c|}{ Tahun } \\
\cline { 2 - 4 } & 2016 & 2017 & 2018 \\
\hline UNSRAT & $39 \%$ & $40 \%$ & $41 \%$ \\
\hline UNIMA & $21 \%$ & $23 \%$ & $21 \%$ \\
\hline UGM & $7 \%$ & $9 \%$ & $8 \%$ \\
\hline ITB & $7 \%$ & $7 \%$ & $9 \%$ \\
\hline UI & $6 \%$ & $5 \%$ & $5 \%$ \\
\hline UNPAD & $5 \%$ & $6 \%$ & $6 \%$ \\
\hline UBM & $2 \%$ & $2 \%$ & $1 \%$ \\
\hline UNUD & $2 \%$ & $2 \%$ & $2 \%$ \\
\hline POLTEKES & $2 \%$ & $1 \%$ & $1 \%$ \\
\hline UNAIR & $1 \%$ & $1 \%$ & $1 \%$ \\
\hline UPH & $3 \%$ & $2 \%$ & $2 \%$ \\
\hline Lainnya & $4 \%$ & $2 \%$ & $3 \%$ \\
\hline
\end{tabular}




\section{Kesimpulan}

Berdasarkan dari hasil analisis dan pembahasan yang dilakukan terhadap 2 sekolah SMA Negeri di MANADO dengan jumlah 315 responden (siswa) yang memilih universitas di Indonesia maka dapat di tarik kesimpulan sebagai berikut : untuk universitas pangsa pasar periode pertama pada tahun 2016 di dominasi oleh UNSRAT sebesar 39\%, kemudian diikuti oleh UNIMA $21 \%$, UGM 7\%, ITB 7\%, UI 6. \%, UNPAD 5\%, UBM 2\%, UNUD 2\%, POLTEKES 2\%, UNAIR 1\%, UPH 3\% dan Lainnya 4\%. Sedangkan pangsa pasar periode berikutnya pada tahun 2018 peluang berubah, walaupun tetap masih di dominasi oleh UNSRAT 41\%, UNIMA $21 \%$, UGM $8 \%$, ITB $9 \%$, UI $5 \%$, UNPAD $6 \%$, UBM $1 \%$, UNUD $2 \%$, POLTEKES $1 \%$, UNAIR $1 \%$, UPH $2 \%$ dan Lainnya $3 \%$.

\section{Daftar Pustaka}

[1] Djan, I., dan Ruvendi, R. 2006. Prediksi Perpindahan Penggunaan Merek Handphone di Kalangan Mahasiswa (Studi Kasus pada Mahasiswa STIE Binaniaga), Jurnal Ilmiah Binaniaga, Vol 2 No.1.

[2] Siswanto. 2007. Operations Research, Jilid Kedua. Erlangga. Jakarta.

[3] Ross, S.M. 2007. Introduction to Probability Models. Eight Edition. Academic Press, Inc. New York.

[4] Ching W.K, and Michael K.Ng. 2006. Markoc Chain Models, Algorithm and Application. Springer. United State Of Amerika.

[5] Howard, A. and Rorres, C. 2004. Aljabar Linear Elementer versi Aplikasi. Edisi ke-8, jilid 2. Terjemahan Izham Harmein dan Julian Gresdando. Erlangga. Jakarta.

[6] Hiller, F. S. and G. J, Lieberman. 2008. Introduction to Operation Research Eight Edition Jilid 2. Penerbit Andi. Jogjakarta. 